Check for updates

Cite this: RSC Adv., 2018, 8, 38410

\title{
Luminescent properties of Eu-doped magnetic $\mathrm{Na}_{3} \mathrm{FeF}_{6} \dagger$
}

\author{
Hong Jia, (DD ${ }^{a}$ Yiping Zhou, ${ }^{a}$ Xiaoyan Wang, ${ }^{a}$ Weiying Zhang, ${ }^{\star a}$ Xun Feng, \\ Zhiang Li, ${ }^{a}$ Hongzhi Fu, ${ }^{a}$ Jianguo Zhao, ${ }^{* a}$ Zhongli Liu (D) *a and Xiaofeng Liu (D) b
}

Sodium iron fluoride $\left(\mathrm{Na}_{3} \mathrm{FeF}_{6}\right)$ is a colorless ferromagnetic fluoride with a monoclinic crystal structure (space group $\mathrm{P} 21 / \mathrm{C}$ ), and it is expected to be an ideal platform for exploring magneto-optical interactions. In the present work, $\mathrm{Eu}^{3+}$ doped $\mathrm{Na}_{3} \mathrm{FeF}_{6}$ micro-powders were synthesized by a hydrothermal method, and the structures were examined by X-ray diffraction (XRD) and scanning electron microscopy (SEM). The optical properties were examined using UV-Vis spectra and fluorescence spectra, and the results show that the emission spectra can be finely tuned by the hydrothermal reaction temperature and doping concentration of Eu ions. We found that $\mathrm{Na}_{3} \mathrm{FeF}_{6}$ doped with $5 \% \mathrm{Eu}^{3+}$ synthesized at $196{ }^{\circ} \mathrm{C}$ exhibited the optimal red emission under excitation at $395 \mathrm{~nm}$. The magnetization of $\mathrm{Na}_{3} \mathrm{FeF}_{6}: 5 \% \mathrm{Eu}^{3+}$ decreased rapidly from about $7.85 \mathrm{emu} \mathrm{g}^{-1}$ at $5 \mathrm{~K}$ to $0.4 \mathrm{emu} \mathrm{g}^{-1}$ at $60 \mathrm{~K}$, then slowly decreased with temperature increase from $60 \mathrm{~K}$ to $300 \mathrm{~K}$. This $\mathrm{Eu}^{3+}$ doped $\mathrm{Na}_{3} \mathrm{FeF}_{6}$ powder is expected to find potential applications in the field of magneto-optical modulation and relevant devices.

Received 27th August 2018 Accepted 8th November 2018

DOI: $10.1039 / \mathrm{c} 8 \mathrm{ra07137c}$

rsc.li/rsc-advances strong (ferromagnetic) magnetic materials can only be realized through the fabrication of core-shell structure, such as the $\mathrm{Fe}_{3} \mathrm{O}_{4} @ \mathrm{Y}_{2} \mathrm{O}_{3}:$ Eu. $^{16}$ However, most ferromagnetic materials including $\mathrm{Fe}_{3} \mathrm{O}_{4}$ strongly absorbs visible light and quenches the emission of the RE ions. ${ }^{17-23}$ Therefore, the search of a colorless magnetic host could be of great interest for the investigation of the magneto-optical effect.

Sodium iron fluoride $\left(\mathrm{Na}_{3} \mathrm{FeF}_{6}\right)$ is a colorless, ferromagnetic fluoride, and it is an ideal platform for the exploration of magneto-optical interactions. ${ }^{24-26}$ In this work, $\mathrm{Na}_{3} \mathrm{FeF}_{6}$ doped with $\mathrm{Eu}^{3+}$ ions were prepared by hydrothermal method. The $\mathrm{Na}_{3} \mathrm{FeF}_{6}$ :Eu powders were characterized with X-ray diffraction (XRD), scanning electron microscopy (SEM). Under excitation by UV light, visible emission can be observed from the $\mathrm{Na}_{3}$ $\mathrm{FeF}_{6}: \mathrm{Eu}$, and luminescence intensity from $\mathrm{Na}_{3} \mathrm{FeF}_{6}: \mathrm{Eu}$ were optimized by adjusting different reaction temperature and doping concentration of $\mathrm{Eu}$ ions. This $\mathrm{Na}_{3} \mathrm{FeF}_{6}$ : $\mathrm{Eu}$ phosphors might be explored as a magneto-optical dual-functional material.

\section{Experimental}

\subsection{Sample synthesis}

The powders of $\mathrm{Fe}\left(\mathrm{NO}_{3}\right)_{3}, \mathrm{NaF}$, and $\mathrm{NH}_{4} \mathrm{HF}_{2}$ were dissolved in deionized water respectively to get a concentration of $0.1 \mathrm{~mol} \mathrm{l}^{-1}$ $\mathrm{Fe}\left(\mathrm{NO}_{3}\right)_{3}, 0.5 \mathrm{~mol} \mathrm{l}^{-1} \mathrm{NaF}$ and $0.5 \mathrm{~mol} \mathrm{l}^{-1} \mathrm{NH}_{4} \mathrm{HF}_{2}$ for each solutions. These solutions were mixed with a volume ratio of $\mathrm{v}$ $\left[\mathrm{Fe}\left(\mathrm{NO}_{3}\right)_{3}\right]: \mathrm{v}[\mathrm{NaF}]: \mathrm{v}\left[\mathrm{NH}_{4} \mathrm{HF}_{2}\right]=1: 1: 3$, and then $3 \mathrm{ml} \mathrm{HF}$ were added into the mixed solutions $(75 \mathrm{ml})$. Finally, $0.1 \mathrm{~mol}^{-1}$ 
$\mathrm{Eu}\left(\mathrm{NO}_{3}\right)_{3}$ was added to the above solution with the volume ratio of $\mathrm{v}[\mathrm{Eu}]: \mathrm{v}[\mathrm{Fe}]=3 \%, 5 \%, 7 \%, 10 \%, 15 \%, 18 \%$. The mixed solution was transferred into an autoclave, and then heated at $196{ }^{\circ} \mathrm{C}$ for 16 hours. After cooling to room temperature, the products were collected from the resultant solutions by centrifugation at $8000 \mathrm{rpm}$ for $20 \mathrm{~min}$. The obtained phosphor powders were washed for three times and then dried at $60{ }^{\circ} \mathrm{C}$.

\subsection{Characterizations}

The crystal structures of all the samples were studied by X-ray diffraction (XRD) with a RIGAKU D/MAX 2550/PC system operated at a step size of $0.02^{\circ}$ at a scanning speed of $5^{\circ} \mathrm{min}^{-1}$ using $\mathrm{Cu} \mathrm{K} \alpha$ radiation $(\lambda=1.5406 \AA)$. Scanning electron microscope (SEM) images were taken using a Hitachi S-4800 scanning electron microscope. The UV-Vis spectra diffuse reflectance spectra of the films were measured at room temperature on a UV-3600 Plus spectrophotometer. The luminescence spectra of the samples were investigated using a Japan F-4600 fluorescence spectrophotometer. Magnetic properties were performed on a Quantum Design SQUID MPMS XL-7 (SQUID).

\section{Results and discussion}

\subsection{Structure of the $\mathrm{Na}_{3} \mathrm{FeF}_{6}$}

Fig. 1a shows the crystal structure of $\mathrm{Na}_{3} \mathrm{FeF}_{6}$ projected along the $a$-axis. The structure of $\mathrm{Na}_{3} \mathrm{FeF}_{6}$ is isomorphic with cryolytelike structures $\left(\mathrm{K}_{2} \mathrm{NaScF}_{6}, \mathrm{Na}_{3} \mathrm{CrF}_{6}\right.$ and $\left.\mathrm{Na}_{3} \mathrm{AlF}_{6}\right)$ with the monoclinic symmetry that belongs to the space group $P 21 / c .^{27,28}$ There are three sodium sites, namely the Na1 site that is located at the distorted octahedral site of $\mathrm{NaF}_{6}$, the $\mathrm{Na} 2$ site at the bipyramidal site of $\left(\mathrm{NaF}_{5}\right)$, and finally the $\mathrm{Na} 3$ site at the distorted tetrahedral site of $\mathrm{NaF}_{4}$ (Fig. 1(b)). All the Fe atoms are located at the distorted $\mathrm{FeF}_{6}$ octahedral sites. Furthermore, it can be observed that Na1 octahedral sites and Na3 tetrahedral sites actually share corner sites. Na1 octahedral sites share edges with Na2 bipyramid sites. Fe-containing octahedrons share corners with $\mathrm{Na} 1$ and $\mathrm{Na} 3$ sites share edges with $\mathrm{Na} 2$ sites.
The $\mathrm{Fe}^{3+}$ ions site can be replaced by $\mathrm{Eu}^{3+}$ ions ions when $\mathrm{Eu}$ ions doping in the $\mathrm{Na}_{3} \mathrm{FeF}_{6}$ structure (Fig. 1a).

\subsection{Characterization of the $\mathrm{Na}_{3} \mathrm{FeF}_{6}$}

Fig. 2 shows the XRD patterns of sodium iron fluoride doped with $\mathrm{Eu}^{3+}$ at concentrations of $3 \%, 5 \%, 7 \%, 10 \%$, and $15 \%$. As concentration of the $\mathrm{Eu}$ ions increase from $3 \%$ to $7 \%$, the diffraction peak gradually shifts to the left, diffraction angle $\theta$ decreases. According to the Bragg equation $(2 d \sin \theta=n \lambda)$, $d$ increases with the decreasing of $\theta$. The reason for this may be that as the concentration of Eu goes up, more $\mathrm{Eu}$ ions are incorporated into the $\mathrm{Na}_{3} \mathrm{FeF}_{6}$ lattice. Compared with $\mathrm{Fe}$ ions, $\mathrm{Eu}$ ions has a larger ionic radius. Therefore, the lattice constant would increase with the increase in the concentration of Eu ions in the lattice. The diffraction peaks of the $\mathrm{Na}_{3} \mathrm{FeF}_{6}$ with $5 \% \mathrm{Eu}^{3+}$ doping are the highest, indicating the best crystallinity. The increase of $\mathrm{Eu}^{3+}$ concentration above $5 \%$ leads to growth of

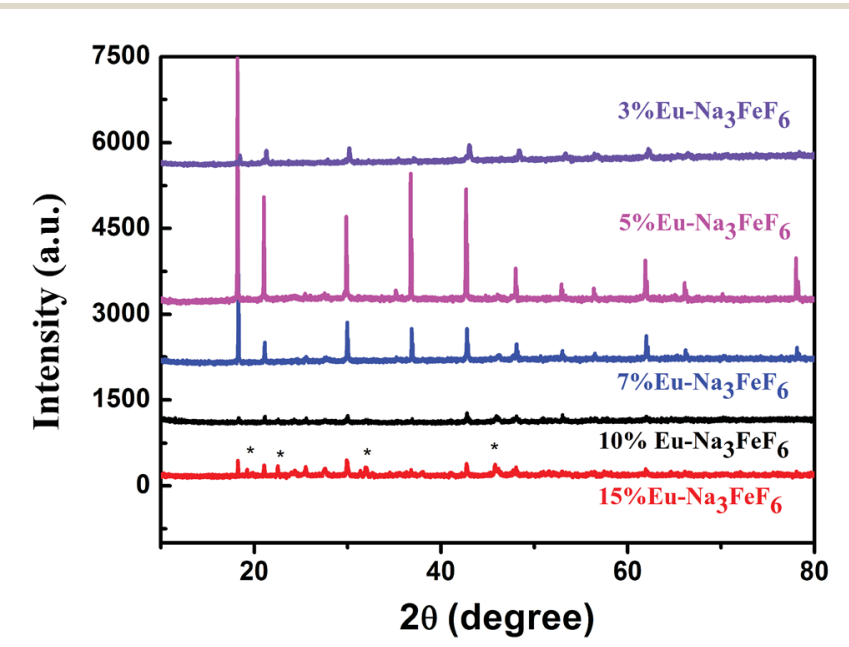

Fig. 2 X-ray diffraction patterns for samples of the $\mathrm{Na}_{3} \mathrm{FeF}_{6}: \mathrm{Eu}^{3+}$ with doping different concentrations of $\mathrm{Eu}^{3+}$. a
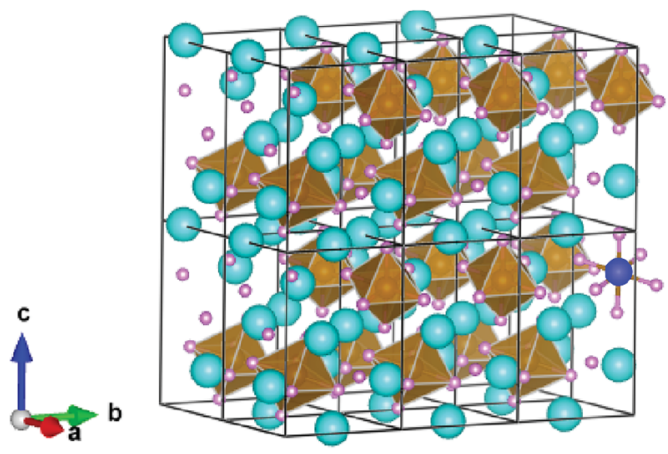

b

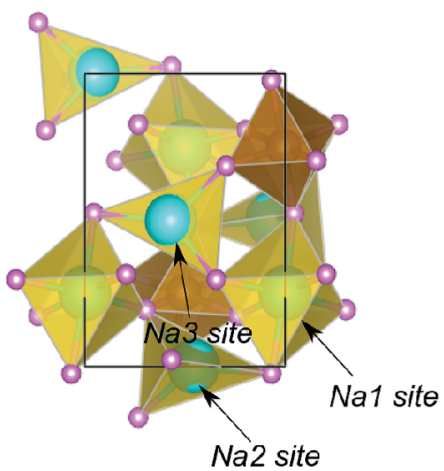

Na2 site

$\mathrm{Na} \odot \mathrm{Fe} \odot \mathrm{F} \bigcirc \mathrm{Eu}$

Fig. 1 (a) Crystal structure of $\mathrm{Na}_{3} \mathrm{FeF}_{6}$ projected along the a axis. (b) A detailed view of three different sodium sites in the $\mathrm{Na}_{3} \mathrm{FeF}_{6} \mathrm{crystal}$ structure. 

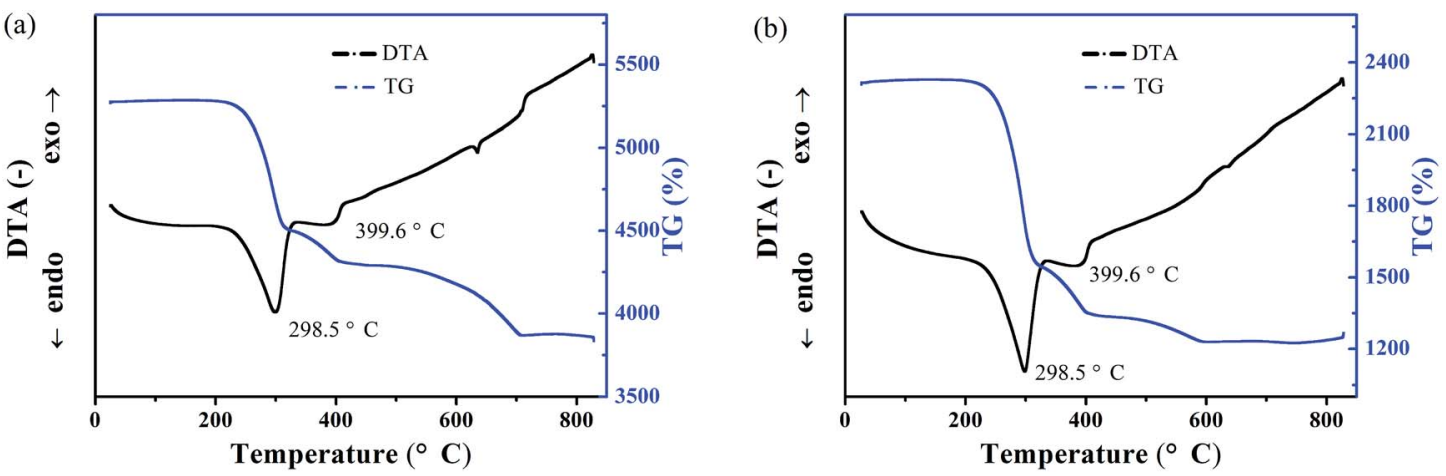

Fig. 3 TG and DTA curves: (a) $\mathrm{Na}_{3} \mathrm{FeF}_{6}$ and (b) $\mathrm{Na}_{3} \mathrm{FeF}_{6}: 5 \% \mathrm{Eu}^{3+}$

lattice strain that prevents the further enhancement of crystallization. As can be seen from the XRD pattern, the solubility limit for $\mathrm{Eu}^{3+}$ ions in the lattice of $\mathrm{Na}_{3} \mathrm{FeF}_{6}$ is lower than $15 \%$, at which considerable amount secondary phase appears due to the collapse of the lattice. ${ }^{6}$ From the thermal analysis, the fluoride host $\mathrm{Na}_{3} \mathrm{FeF}_{6}$ is stable at temperatures up to around $255^{\circ} \mathrm{C}$. At higher temperatures, a strong endothermic peak appears accompanied with high weight loss in multiple stages, indicating the decomposition of the material (Fig. 3a). The detailed reactions involved in the decomposition remain to the unraveled. TG-TDA curver of $\mathrm{Na}_{3} \mathrm{FeF}_{6}: 5 \% \mathrm{Eu}^{3+}$ is similarity with the pristine $\mathrm{Na}_{3} \mathrm{FeF}_{6}$ powder, indicating that the structure of the $\mathrm{Na}_{3} \mathrm{FeF}_{6}$ is stable when the $5 \% \mathrm{Eu}^{3+}$ doping in $\mathrm{Na}_{3} \mathrm{FeF}_{6}$.

Fig. 4 and S2a $\uparrow$ presents the typical SEM images of powders of $\mathrm{Na}_{3} \mathrm{FeF}_{6}$ doped with $5 \% \mathrm{Eu}^{3+}$ and pristine $\mathrm{Na}_{3} \mathrm{FeF}_{6}$ powder. Octahedral particles are clearly observed, which is in accordance with the crystal structure of $\mathrm{Na}_{3} \mathrm{FeF}_{6}$ (Fig. 1), The average radius of these particles is around $4 \mu \mathrm{m}$ and the surfaces of the particles are not smooth. The SEM image and the corresponding energy-dispersive spectrum EDS of the $\mathrm{Na}_{3} \mathrm{FeF}_{6}: 5 \% \mathrm{Eu}$ (Fig. S1†) and pristine $\mathrm{Na}_{3} \mathrm{FeF}_{6}$ powder (Fig. $\mathrm{S} 3 \dagger$ ) shows elemental distribution of $\mathrm{Na}, \mathrm{Fe}$ and $\mathrm{F}$ is revealed by elemental energy spectrum analysis and elemental Eu distribution in the $\mathrm{Na}_{3} \mathrm{FeF}_{6}: 5 \% \mathrm{Eu}$ structure. Fig. S2b $\dagger$ shows the images of powders of $\mathrm{Na}_{3} \mathrm{FeF}_{6}$ doped with $15 \% \mathrm{Eu}^{3+}$ including both octahedral particles and secondary phase with nanorod. The results in accordance with the XRD pattern from $\mathrm{Na}_{3} \mathrm{FeF}_{6}: 15 \%$ Eu. Fig. $4 \mathrm{c}-\mathrm{f}$ show the SEM image and the corresponding EDS mapping images of $\mathrm{Fe}, \mathrm{Na}, \mathrm{F}$ and Eu elements. The result shows that all of the elements were detected and uniformly distributed.

\subsection{Photoluminescence properties}

Fig. 5 shows the absorption spectra of $\mathrm{Na}_{3} \mathrm{FeF}_{6}$ doped with different concentrations of $\mathrm{Eu}^{3+}(3 \%, 5 \%, 7 \%, 10 \%, 15 \%$ and

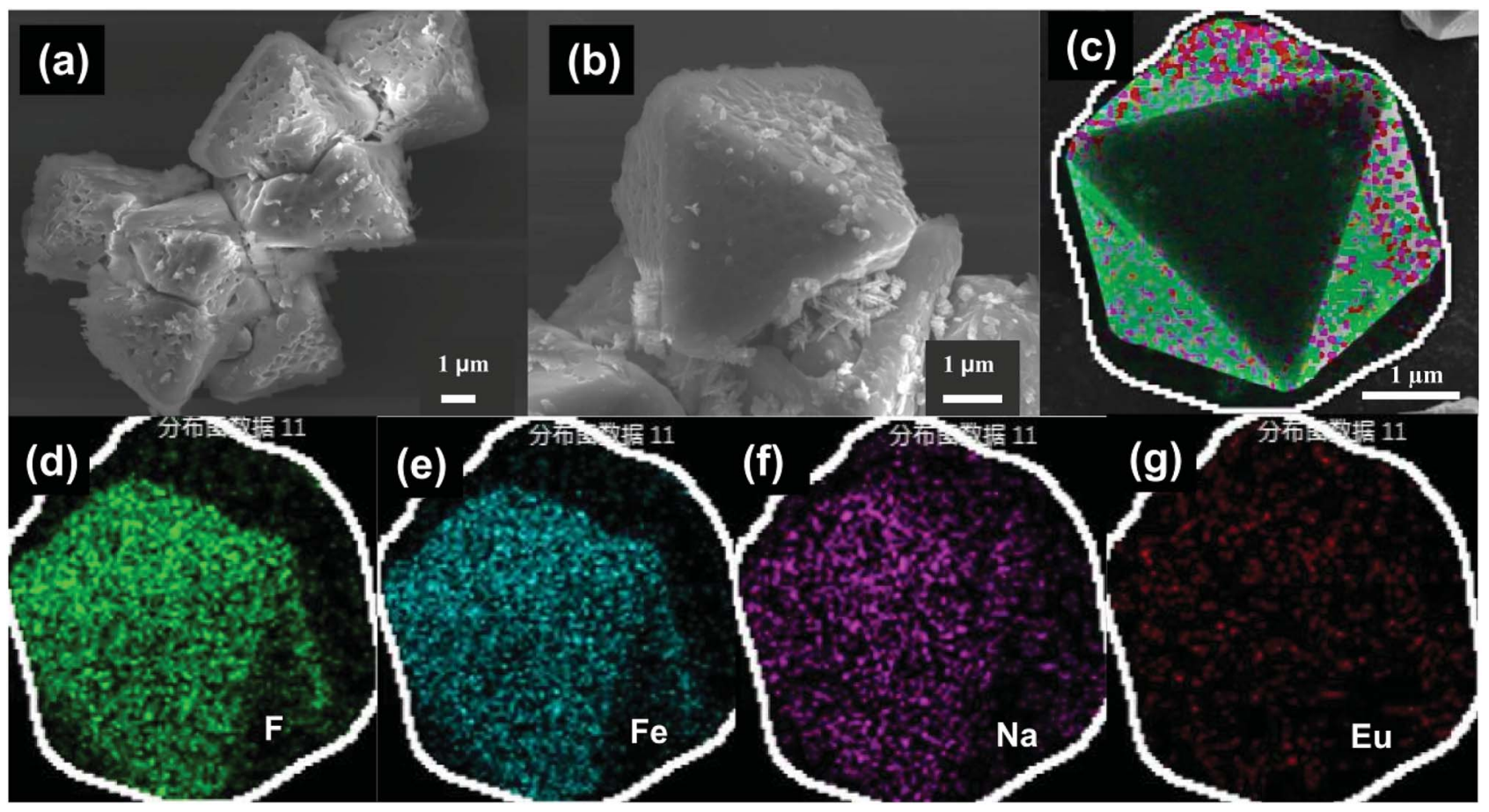

Fig. 4 SEM images image of the $\mathrm{Na}_{3} \mathrm{FeF}_{6}: 5 \% \mathrm{Eu}^{3+}$ powders and the corresponding EDS mapping images of $\mathrm{F}$, Fe, $\mathrm{Na}$ and Eu elements. 


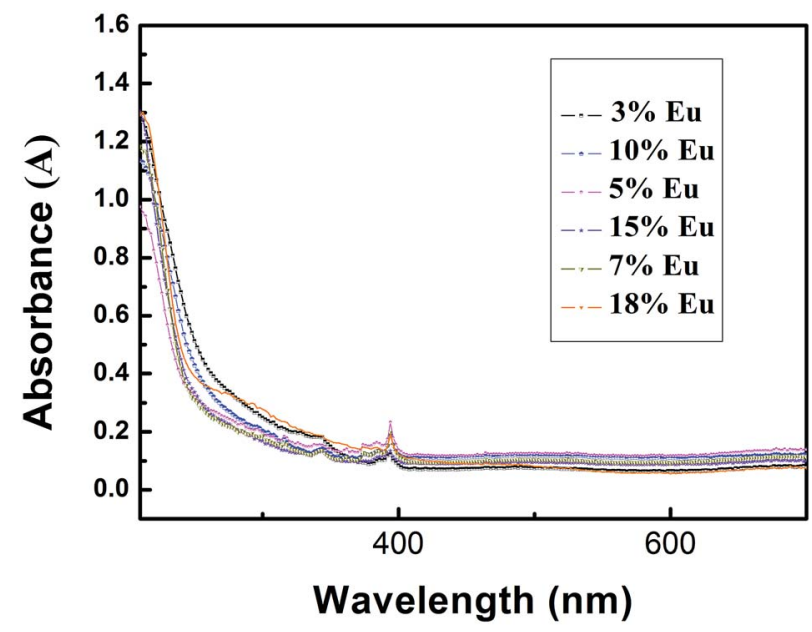

Fig. 5 Absorption spectra of the $\mathrm{Na}_{3} \mathrm{FeF}_{6}$ powder doped with different concentrations of $\mathrm{Eu}^{3+}$.

$18 \%$ ) in the spectral range of $200-750 \mathrm{~nm}$. It can be clearly seen that the Eu-doped $\mathrm{Na}_{3} \mathrm{FeF}_{6}$ powders exhibit obvious ultraviolet absorption at wavelength short than $300 \mathrm{~nm}$. A small peak located at $395 \mathrm{~nm}$ can be attributed to the $\mathrm{f}-\mathrm{f}$ transition of $\mathrm{Eu}^{3+}$, while other transitions are not observed due to their weak transition probability. Obviously, the intensity of absorbance at $395 \mathrm{~nm}$ increases from $3 \% \mathrm{Eu}$ to $5 \% \mathrm{Eu}$ doped samples. At doping concentrations higher than $10 \%$, the absorbance does not increase further, implying the doping limit of RE ions in the host of $\mathrm{Na}_{3} \mathrm{FeF}_{6}$.

As shown in Fig. 6a, the excitation spectra of $5 \% \mathrm{Eu}^{3+}$ doped $\mathrm{Na}_{3} \mathrm{FeF}_{6}$ are measured at the wavelength of $615 \mathrm{~nm}$. It can be observed from the excitation spectrum that there is a strong excitation band between $380-400 \mathrm{~nm}$ with a peak at around $395 \mathrm{~nm}$, which can be well ascribed to the different $\mathrm{f}-\mathrm{f}$ transitions of $\mathrm{Eu}^{3+}$. Fig. $6 \mathrm{~b}$ presents the emission spectra of $\mathrm{Na}_{3} \mathrm{FeF}_{6}$ doped with different concentrations of $\mathrm{Eu}^{3+}$ ions. The strongest emission peak is at $615 \mathrm{~nm}$, which is attributed to the ${ }^{5} \mathrm{D}_{0}-{ }^{7} \mathrm{~F}_{2}$ transitions of $\mathrm{Eu}^{3+} \cdot{ }^{12}$ Increase of the $\mathrm{Eu}^{3+}$ doping level leads to the growth of emission intensity and the strongest intensity is observed for $5 \% \mathrm{Eu}^{3+}$ doping. At doping levels higher than 5\%, the emission intensity no longer increases due to concentration quenching. It is generally explained by the competition of two parallel processes: the emission process and the quenching process by self-absorption as well as cross-relaxation between $\mathrm{Eu}^{3+}$ ions. ${ }^{7}$ At low $\mathrm{Eu}^{3+}$ doping concentrations, ion-ion interaction is negligibly small. ${ }^{8}$ Above a certain $\mathrm{Eu}^{3+}$ concentration, the interactions between nearby $\mathrm{Eu}^{3+}$ ions becomes strong, which provides new energy dissipation pathways and reduces the rate of emission. ${ }^{9}$

Fig. $6 c$ shows the emission spectra of the $\mathrm{Na}_{3} \mathrm{FeF}_{6}: 5 \% \mathrm{Eu}^{3+}$ powders (the $5 \% \mathrm{Eu}^{3+}$ doping $\mathrm{Na}_{3} \mathrm{FeF}_{6}$ was optimized from the Fig. 6b) synthesized at different temperatures. Under the excitation at $395 \mathrm{~nm}$, the emission spectra show two peaks at $596 \mathrm{~nm}$ and $615 \mathrm{~nm}$, respectively. The stronger peak at $615 \mathrm{~nm}$
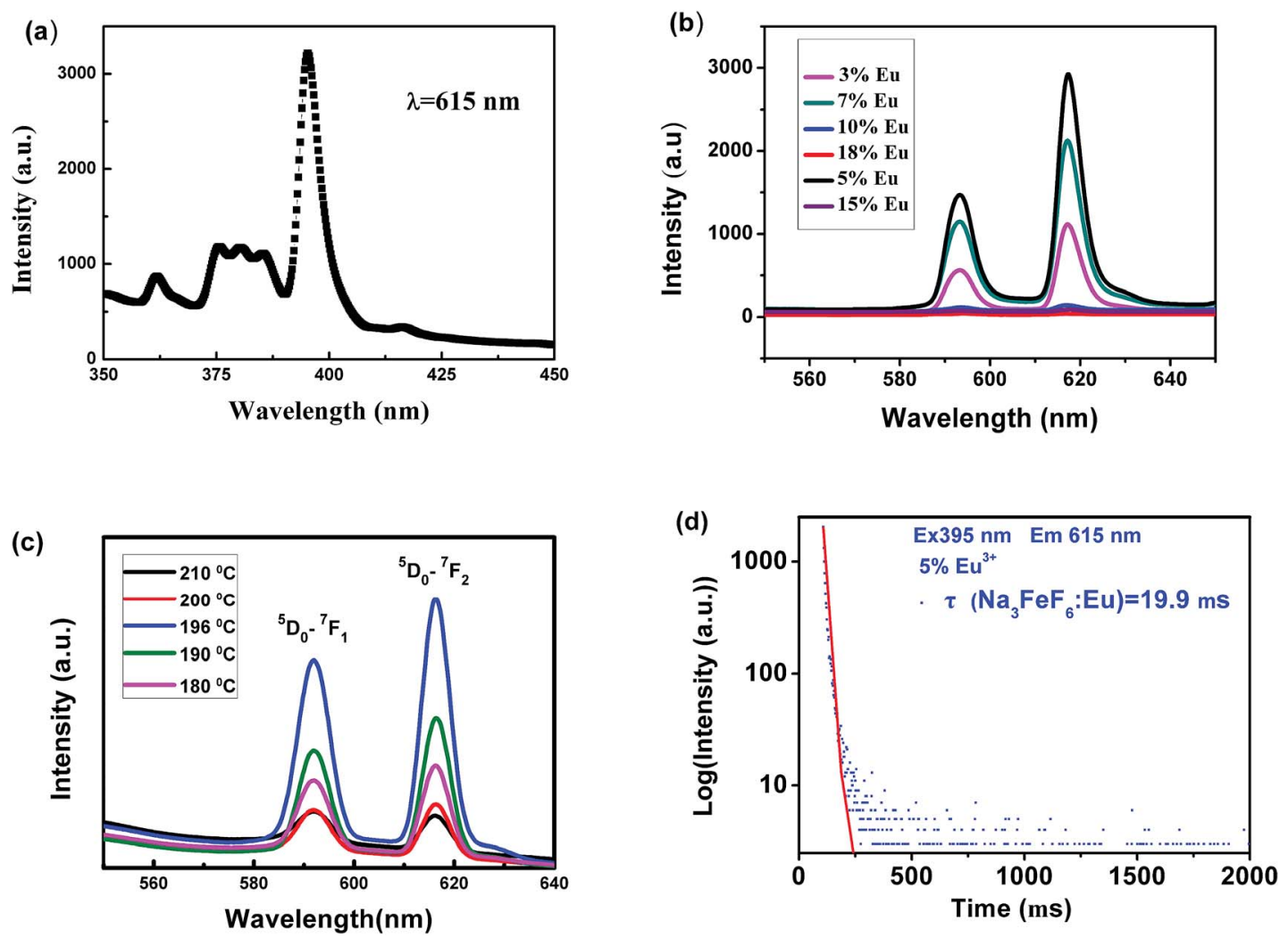

Fig. 6 (a) Excitation spectrum of $\mathrm{Na}_{3} \mathrm{FeF}_{6}: 5 \% \mathrm{Eu}^{3+}$. (b) Emission spectra of $\mathrm{Na}_{3} \mathrm{FeF}_{6}$ doped with different concentration of Eu ${ }^{3+}$. (c) Emission spectra of the $\mathrm{Na}_{3} \mathrm{FeF}_{6}: 5 \% \mathrm{Eu}^{3+}$ synthesized at different temperature. (d) Decay curves of the red (615 nm) emission under pulsed $395 \mathrm{~nm}$ excitation for the powder of $\mathrm{Na}_{3} \mathrm{FeF}_{6}: 5 \% \mathrm{Eu}^{3+}$. 

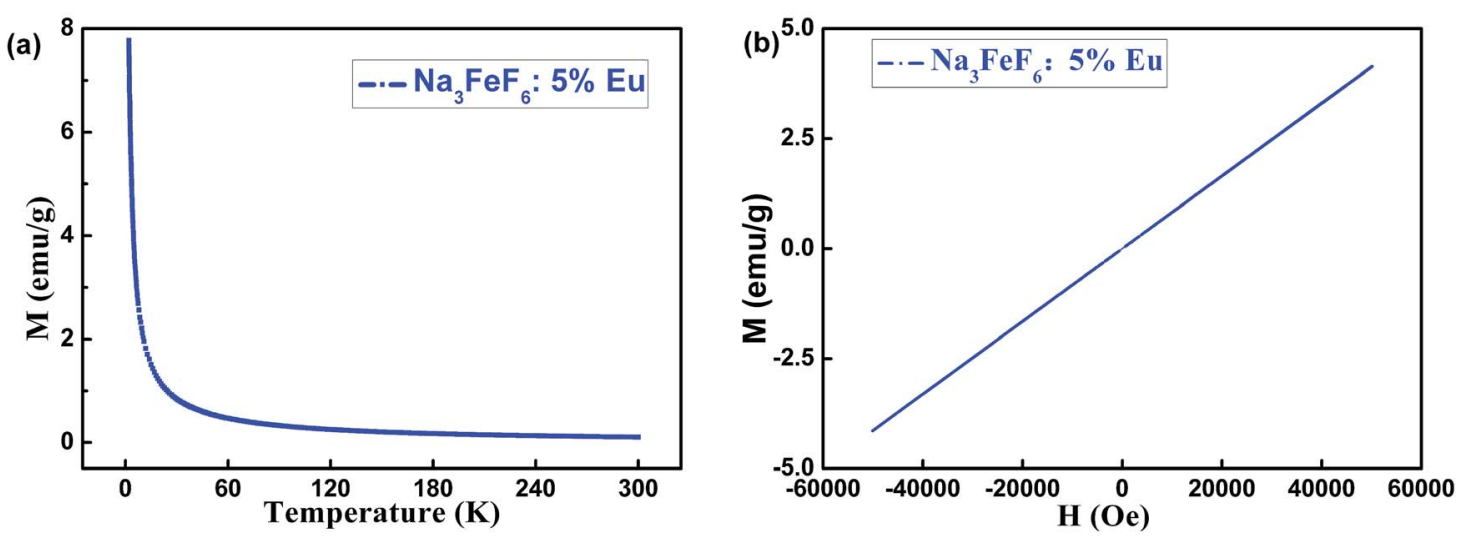

Fig. 7 The magnetization curve of $\mathrm{Na}_{3} \mathrm{FeF}_{6}: 5 \% \mathrm{Eu}^{3+}$ particle at different temperature (a) and $300 \mathrm{~K}$ (b).

is due to the ${ }^{5} \mathrm{D}_{0}{ }^{-}{ }^{7} \mathrm{~F}_{2}$ transition of the $\mathrm{Eu}$ ions and the other peak at $596 \mathrm{~nm}$ is owing to ${ }^{5} \mathrm{D}_{0}-{ }^{7} \mathrm{~F}_{1}$ transition. The emission intensity is the highest for the sample obtained at $196{ }^{\circ} \mathrm{C}$, and a higher synthesis temperature is not favorable for improving optical property. The decay curves of red $(615 \mathrm{~nm})$ emission was measured under pulsed $395 \mathrm{~nm}$ excitation (Fig. 6d). By fitting the decay curve with a bi-exponential decay function, we obtain a lifetime of $19.9 \mathrm{~ms}$, which fall into the typical value for the red emission of $\mathrm{Eu}^{3+}$.

The magnetization properties of $\mathrm{Na}_{3} \mathrm{FeF}_{6}: 5 \% \mathrm{Eu}^{3+}$ particle was detected during warming up from $5 \mathrm{~K}$ to $300 \mathrm{~K}$ under field of 1000 Oe was applied. It was observed that the magnetization decrease rapidly from about $7.85 \mathrm{emu} \mathrm{g}^{-1}$ at $5 \mathrm{~K}$ to $0.4 \mathrm{emu} \mathrm{g}^{-1}$ at $60 \mathrm{~K}$, then slowly decreasing with temperature increase from $60 \mathrm{~K}$ to $300 \mathrm{~K}$ (Fig. 7). The magnetization versus magnetic field $(M-H)$ curves of $\mathrm{Na}_{3} \mathrm{FeF}_{6}: 5 \% \mathrm{Eu}^{3+}$ particle by SQUID under the maximum magnetic field of $50000 \mathrm{Oe}$ at $300 \mathrm{~K}$. It can be seen that the magnetization increase linearly from $-4.15 \mathrm{emu}^{-1}$ to $4.14 \mathrm{emu} \mathrm{g}^{-1}$ under magnetic field from -50000 Oe to 5000 Oe. The results considered that $\mathrm{Na}_{3} \mathrm{FeF}_{6}: 5 \% \mathrm{Eu}^{3+}$ is paramagnetic material. Fig. $\mathrm{S} 5 \dagger$ shows the magnetization curves of $\mathrm{Na}_{3} \mathrm{FeF}_{6}$ doped with different concentration of $\mathrm{Eu}^{3+}$ ions at $300 \mathrm{~K}$. Increase of the $\mathrm{Eu}^{3+}$ doping level leads to the decrease of paramagnetic intensity, it maybe due to the higher paramagnetic intensity from $\mathrm{Fe}^{3+}$ ions compare with $\mathrm{Eu}^{3+}$ ions and the positions of $\mathrm{Fe}^{3+}$ ions in $\mathrm{Na}_{3} \mathrm{FeF}_{6}$ structure were gradually replaced by the $\mathrm{Eu}^{3+}$ ions.

\section{Conclusions}

The phosphor powder of $\mathrm{Na}_{3} \mathrm{FeF}_{6}: \mathrm{Eu}$ is prepared by hydrothermal method. The structures of the $\mathrm{Na}_{3} \mathrm{FeF}_{6}: \mathrm{Eu}$ powders were characterized by X-ray diffraction (XRD) and SEM. Octahedral particles with homogeneous surfaces are obtained. Optical measurement indicates that $\mathrm{Na}_{3} \mathrm{FeF}_{6}$ doped with $5 \%$ $\mathrm{Eu}^{3+}$ and synthesized at the temperature of $196{ }^{\circ} \mathrm{C}$ shows the strongest emission intensity. The magnetization of $\mathrm{Na}_{3} \mathrm{FeF}_{6}: 5 \%$ $\mathrm{Eu}^{3+}$ decrease rapidly from about $7.85 \mathrm{emu} \mathrm{g}^{-1}$ at $5 \mathrm{~K}$ to $0.4 \mathrm{emu}$ $\mathrm{g}^{-1}$ at $60 \mathrm{~K}$, then slowly decreasing with temperature increase from $60 \mathrm{~K}$ to $300 \mathrm{~K}$. The results pave the way for the study of the magneto-optical effect in this material.

\section{Conflicts of interest}

There are no conflicts to declare.

\section{Acknowledgements}

This work was financially supported by the National Key R\&D Program of China (Grant No. 2018YFB1107200), the National Natural Science Foundation of China (Grant No. 61404071, 61575091, 61675094, 51132004, 51072054, 51102209, 51472091, 51772270 and 51471082), Key projects of Henan Provincial Education Department (No. 16A140029 and No. 14B40010), the National Basic Research Program of China (2011CB808100), the Natural Science Foundation of Henan Province of China (162300410201), the Henan Provincial Department of Science and Technology Research Project (162102210303), the Fundamental and Cutting-edge Technology Research Program of Henan Province (152300410218), the Key Scientific Research Projects of Henan Province (Grants 16A140014 and 16A140016), the Program for Young Teachers of Higher School in Henan Province (2013GGJS-153), the Program for Innovation Talents (in Science and Technology) in University of Henan Province (16HASTIT044), Youth Backbone Teacher Training Program in Henan province (2017GGJS137) Open funds of State Key Laboratory of Precision Spectroscopy, East China Normal University and State Key Laboratory of High Field Laser Physics, Shanghai Institute of Optics and Fine Mechanics, Chinese Academy of Sciences.

\section{References}

1 H. Yun, M. S. Ahmed, K. Lee, S. Jeon and C. W. Lee, Potential enhancement of antibacterial activity of graphene oxidesilver nanocomposite by introducing $\mathrm{C}_{2}$ carbon chain linkage, Appl. Surf. Sci., 2016, 360, 915-920.

2 H. Jia, Z. Chen, Z. L. Liu, J. G. Zhao, C. L. Ding, H. F. Yang, W. Y. Zhang, X. F. Liu and J. R. Qiu, $\mathrm{CaF}_{2}: \mathrm{Eu}$ films shine novel blue, white or red luminescence though adjustment of the valence state of Eu ions using the electro-deposition method, J. Mater. Chem. C, 2017, 5, 12085-12089. 
3 X. W. Zhang, Y. Y. Liu, J. Gao, G. S. Han, M. F. Hu, X. L. Wu, H. Q. Cao, X. Y. Wang and B. J. Li, Defect-rich (Co-CoS 2 ) $\mathrm{x} @ \mathrm{Co}_{9} \mathrm{~S}_{8}$ nanosheets derived from monomolecular precursor pyrolysis with excellent catalytic activity for hydrogen evolution reaction, J. Mater. Chem. A, 2018, 6, 7977-7987.

4 N. N. Sulaiman, N. S. Mustafa and M. Ismail, Effect of $\mathrm{Na}_{3} \mathrm{FeF}_{6}$ catalyst on the hydrogen storage properties of $\mathrm{MgH}_{2}$, Dalton Trans., 2016, 45, 7085-7093.

5 H. Q. Wang, M. Batentschuk, A. Osvet, L. Pinna and C. J. S. Brabec, Rare-earth ion doped up-conversion materials for photovoltaic applications, Adv. Mater., 2011, 23, 2675-2680.

6 S. Güner, M. Amir, M. Geleri, M. Sertkol and A. Baykal, Magneto-optical Properties $\mathrm{Mn}^{3+}$ substituted $\mathrm{Fe}_{3} \mathrm{O}_{4}$ nanoparticles, Ceram. Int., 2018, 11, 324-329.

7 A. Mehta, T. Thundat, M. D. Barnes, V. Chhabra, R. Bhargava, A. P. Bartko and R. M. Dickson, Sizecorrelated spectroscopy and imaging of rare-earth-doped nanocrystals, Appl. Opt., 2003, 42, 2132-2139.

8 T. H. Shin, Y. Choi, S. Kim and S. J. Cheon, Recent advances in magnetic nanoparticle-based multi-modal imaging, Chem. Soc. Rev., 2015, 44, 4501-4516.

9 L. Zeng, L. Luo, Y. Pang, S. Luo, G. Lu and A. Wu, In vivo targeted magnetic resonance imaging and visualized photodynamic therapy in deep-tissue cancers using folic acid-functionalized superparamagnetic upconversion nanocomposites, Nanoscale, 2015, 7, 8946-8954.

10 M. L. Zhang, Z. G. Xia and Q. L. Liu, Thermally stable $\mathrm{K}_{x} \mathrm{Cs}_{1-x} \mathrm{AlSi}_{2} \mathrm{O}_{6}: \mathrm{Eu}^{2+}$ phosphors and their photoluminescence tuning, J. Mater. Chem. C, 2017, 5, 7489-7494.

11 T. Guo, Y. Lin, W. J. Zhang, J. S. Hong, R. H. Lin, X. P. Wu, C. H. Lu and H. H. Yang, High-efficiency X-ray luminescence in $\mathrm{Eu}^{3+}$-activated tungstate nanoprobes for optical imaging through energy transfer sensitization, Nanoscale, 2018, 10, 1607-1612.

12 M. J. Zhong, M. P. Hedges, R. L. Ahlefeldt, J. G. Bartholomew, S. E. Beavan, S. M. Wittig, J. J. Longdell and M. J. Sellars, Optically addressable nuclear spins in a solid with a sixhour coherence time, Nature, 2015, 517, 177-180.

13 D. Q. Chen, Z. Y. Wan, X. Chen, Y. J. Yuan and J. S. Zhong, Large-scale room-temperature synthesis and optical properties of perovskite related $\mathrm{Cs}_{4} \mathrm{PbBr}_{6}$ fluorophores, $J$. Mater. Chem. C, 2016, 4, 10646-10653.

14 J. J. H. A. VanHest, G. A. Blab, H. C. Gerritsen, G. D. M. Donega and A. Meijerink, Probing the Influence of Disorder on Lanthanide Luminescence Using Eu-Doped $\mathrm{LaPO}_{4}$ Nanoparticles, J. Phys. Chem. C, 2017, 121, 1937319382.

15 H. X. Peng, B. Cui, G. M. Li, Y. S. Wang, N. N. Li, Z. G. Chang and $Y$. Y. Wang, A multifunctional $\beta$-CD-modified $\mathrm{Fe}_{3} \mathrm{O}_{4} @ \mathrm{ZnO}: \mathrm{Er}^{3+}, \mathrm{Yb}^{3+}$ nanocarrier for antitumor drug delivery and microwave-triggered drug release, Mater. Sci. Eng., C, 2015, 46, 253-263.
16 D. Q. Chen, W. W. Wu, Y. J. Yuan, Y. Zhou, Z. Y. Wan and P. Huang, Intense multi-state visible absorption and fullcolor luminescence of nitrogen-doped carbon quantum dots for blue-light-excitable solid-state-lighting, J. Mater. Chem. C, 2016, 4, 9027-9035.

17 J. Q. Wan, Q. Liu, G. H. Liu, Z. Z. Zhou, J. Ni and R. J. Xie, A novel $\mathrm{Eu}^{2+}$ activated $\mathrm{G}-\mathrm{La}_{2} \mathrm{Si}_{2} \mathrm{O}_{7}$ phosphor for white LEDs: SiC-reduction synthesis, tunable luminescence and good thermal stability, J. Mater. Chem. C, 2017, 5, 1614-1623.

18 Q. L. Ma, J. X. Wang, X. T. Dong, W. S. Yu and G. X. Liu, Magnetic-upconversion luminescent bifunctional flexible coaxial nanoribbon and Janus nanoribbon: one-pot electrospinning preparation, structure and enhanced upconversion luminescent characteristics, Chem. Eng. J., 2015, 260, 222-230.

19 G. F. Wang, Q. Peng and Y. D. Li, Lanthanide-doped nanocrystals: synthesis, optical-magnetic properties, and applications, Acc. Chem. Res., 2011, 44, 322-332.

20 V. Shanmugam, S. Selvakumar and C. S. Yeh, Near-infrared light-responsive nanomaterials in cancer therapeutics, Chem. Soc. Rev., 2014, 43, 6254-6287.

21 A. Kumar, A. Kumar, G. Sharma, A. H. Al-muhtaseb, M. Naushad, A. A. Ghfar and F. J. Stadler, Quaternary magnetic $\mathrm{BiOCl} / \mathrm{g}-\mathrm{C}_{3} \mathrm{~N}_{4} / \mathrm{Cu}_{2} \mathrm{O} / \mathrm{Fe}_{3} \mathrm{O}_{4}$ nano-junction for visible light and solar powered degradation of sulfamethoxazole from aqueous environment, Chem. Eng. J., 2018, 334, 462-478.

22 S. Y. Yu, X. C. Gao, H. Jing, R. H. Zhang, X. L. Gao and H. Q. Su, Fabrication and characterization of novel magnetic/luminescent multifunctional nanocomposites for controlled drug release, CrystEngComm, 2014, 16, 66456653.

23 H. Wang, Z. Y. Wei, H. Matsui and S. Q. Zhou, $\mathrm{Fe}_{3} \mathrm{O}_{4} /$ carbon quantum dots hybrid nanoflowers for highly active and recyclable visible-light driven photocatalyst, J. Mater. Chem. A, 2014, 2, 15740-15745.

24 H. R. Yin, Y. Gao, R. Buchanan, J. B. Song and M. Y. Li, Wavelength dependence of $\mathrm{Tb}^{3+}$ doped magneto-optical glass Verdet constant, Ceram. Int., 2018, 44, 10929-10933.

$25 \mathrm{~L}$. Wang and Y. D. Li, $\mathrm{Na}\left(\mathrm{Y}_{1.5} \mathrm{Na}_{0.5}\right) \mathrm{F}_{6}$ Single-Crystal Nanorods as Multicolor Luminescent Materials, Nano Lett., 2006, 6, 1645-1649.

26 K. He, Y. N. Zhou, P. Gao, L. P. Wang, N. Pereira, G. G. Amatucci, K. W. Nam, X. Q. Yang, Y. M. Zhu, F. Wang and D. Su, Sodiation via Heterogeneous Disproportionation in $\mathrm{FeF}_{2}$ Electrodes for Sodium-Ion Batteries, ACS Nano, 2014, 8, 7251-7259.

27 E. H. Song, J. Q. Wang, S. Ye, X. F. Jiang, M. Y. Peng and Q. Y. Zhang, Room-temperature synthesis and warm-white LED applications of $\mathrm{Mn}^{4+}$ ion doped fluoroaluminate red phosphor $\mathrm{Na}_{3} \mathrm{AlF}_{6}: \mathrm{Mn}^{4+}$, J. Mater. Chem. C, 2016, 4, 24802487.

28 G. Brunton, The crystal structure of $\mathrm{Na}_{3} \mathrm{CrF}_{6}$, Mater. Res. Bull., 1969, 4, 621-626. 